\title{
Conversation and Object Manipulation Influence Children's Learning in a Museum
}

\author{
Erin A. Jant and Catherine A. Haden \\ Loyola University Chicago
}

\author{
David H. Uttal \\ Northwestern University
}

\author{
Elizabeth Babcock \\ The Field Museum
}

\begin{abstract}
The effects of parent-child conversation and object manipulation on children's learning, transfer of knowledge, and memory were examined in two museum exhibits and conversations recorded at home. Seventyeight children $\left(M_{\mathrm{age}}=4.9\right)$ and their parents were randomly assigned to receive conversation cards featuring elaborative questions about exhibit objects, the physical objects themselves, both, or neither, before their exhibit visits. Dyads who received the cards engaged in more elaborative talk and joint nonverbal activities with objects in the first exhibit than those who did not. Dyads who received objects engaged in the most parentchild joint talk. Results also illustrate transfer of information across exhibits and from museum to home. Implications for understanding mechanisms of informal learning and transfer are discussed.
\end{abstract}

Experiences in museums can be a key to children's developing interest and understanding of culture and science. Researchers and educators have stressed that these informal educational experiences are important in the science, technology, engineering, and math (STEM) learning process (e.g., Bell, Lewnstein, Shouse, \& Feder, 2009; National Science Board, 2010). Young children learn in museums through a combination of hands-on manipulation of objects and conversations with others (Bell et al., 2009; Falk \& Dierking, 2000). These two sources of information may have synergistic effects on STEM learning in the early years. In our research in a natural history museum, we focused on whether and how children's activities with objects and parentchild conversations influence learning about cultural practices and scientific discovery.

\section{Hands-On Learning and Transfer}

The idea that children learn through direct experience interacting with objects is one of the oldest

This report is based on work supported by the Spencer Foundation under Grant 200800123, and the National Science Foundation under Grant 1123411. We thank Iris Chin, Philip Hoffman, Nathaniel G. Meadow, Jessica Omelanczuk, Eleanor Tushman, and Sarah Uttal. We also thank The Field Museum staff members and the families who made this work possible.

Correspondence concerning this article should be addressed to Catherine A. Haden, Loyola University Chicago, Department of Psychology, 1032 West Sheridan Road, Chicago, IL 60660. Electronic mail may be sent to chaden@luc.edu.
(Piaget, 1970; Vygotsky, 1978) and most consistently applied ideas in developmental psychology, education, and learning science. Work on embodied cognition, for example, has emphasized the importance of physical actions in learning and representation (Auslander, 2001; Glenberg, Brown, \& Levin, 2007; Núñez, 2000). That museum exhibits for children are designed to encourage hands-on engagement also reflects the notion that children learn best through direct action with objects (Leinhardt, Crowley, \& Knutson, 2002; Paris \& Hapgood, 2002).

Nevertheless, researchers have identified potential limitations with this method of learning. First, attractive, hands-on displays may grab children's attention, but this alone is not enough to ensure further engagement with the underlying ideas and learning (e.g., Narayanan \& Hegarty, 2000). A second concern is whether children will use what they learn through object manipulation in new or different contexts (e.g., from museum to home and/or school). Cognitive and learning psychologists typically refer to these issues as problems of transfer of knowledge, and at least initially, psychological research suggested that transfer was difficult or fleeting when it existed at all (Gick \& Holyoak,

(C) 2014 The Authors

Child Development (C) 2014 Society for Research in Child Development, Inc. All rights reserved. 0009-3920/2014/8505-0021

DOI: $10.1111 /$ cdev. 12252 
1983; Ross, 1989). Likewise, although many studies have demonstrated the value of object manipulation for early learning, very few have demonstrated that such learning consistently transfers to new contexts (McNeil \& Uttal, 2009; Uttal, Liu, \& DeLoache, 2006; Uttal, O'Doherty, Newland, Hand, \& DeLoache, 2009; Uttal et al., 2013). Representing knowledge in a manner that makes it portable and applicable across contexts may be particularly challenging when that knowledge is acquired from extensive interaction with objects.

Importantly, recent work on transfer from education and the learning sciences has led to a substantial change in how we conceive of and study transfer-and documentation of much greater success. Bransford and Schwartz (1999) argued that traditional psychology studies have relied too much on what they termed the sequestered nature of laboratory-based learning. To provide "pure" tests of transfer, participants are intentionally cut off from supporting sources of information, including (usually) other people. Problem solving and learning, particularly for young children, almost always occurs in a sociocultural context. Moreover, transfer is not simply moving knowledge from one context to another; instead, it is the linking of two learning environments, which includes not only the individual learner but also the physical and social resources in those environments. The social context provides the elements that are necessary for the emergence of everyday expertise (Zimmerman, Reeve, \& Bell, 2009), and prior culturally mediated experiences can serve as key bases (or epistemic resources) for linking prior experiences with present activities, learning, and problem solving. Successful transfer will often involve what Engle (2006) termed intercontextuality: when the original and transfer contexts are explained and learned in ways that emphasize relations among them. This broader perspective on transfer requires that we rethink the methods and measures that are used to study it. Transfer cannot be easily measured, at least successfully, through single tests involving only the learner. Measuring transfer will involve not only what is learned but also how it is framed (e.g., by parents).

\section{Learning Through Conversation}

Parent-child conversations may provide a critical mechanism for learning and transfer of knowledge. Our analysis draws on research guided by sociocultural theory (Rogoff, 1990; Vygotsky, 1978), demonstrating that parent-child conversations during events are related to children's understanding and memory for the events (e.g., Haden, Ornstein, Eckerman, \& Didow, 2001; Hedrick, San Souci, Haden, \& Ornstein, 2009; McGuigan \& Salmon, 2006; Tessler \& Nelson, 1994). Moreover, other research on children's STEM learning in museums (e.g., Bell et al., 2009; Callanan \& Jipson, 2001; Crowley \& Jacobs, 2002; Crowley et al., 2001; Ellenbogen, 2002; Palmquist \& Crowley, 2007; Rigney \& Callanan, 2011) points to particular forms of conversation that may be especially important for learning (see Haden, 2010, for discussion). For example, parents' open-ended questions (e.g., What, Why, and How) can facilitate children's understanding by focusing attention on salient aspects of an exhibit object or activity and eliciting information from children in an effort to diagnose what they do (and do not) know. If the parent's Wh-question is followed by the child's response- such as when the parent asks, "What do you think these arrowheads were used for?" and the child says, "For hunting"- the joint talk that results can also predict learning and remembering (e.g., Hedrick et al., 2009).

Wh-questions present a form of social support that can work to advance children's everyday observations of and physical engagement with objects to specific knowledge of a topic (see Eberbach \& Crowley, 2009). But in some cases, when knowledge is lacking and questions are not met with child responses, Wh-questions may lead to parents' explanations. Associations - questions and statements that help children link prior knowledge and experiences to present (and future) learning (e.g., Boland, Haden, \& Ornstein, 2003; Crowley et al., 2001; Tessler \& Nelson, 1994) - have been identified as an especially important form of explanation for children's STEM learning in museums (e.g., Bell et al., 2009; Callanan \& Jipson, 2001; Crowley \& Jacobs, 2002; Tenenbaum \& Callanan, 2008). Indeed, several studies have illustrated how providing connections to previous experiences can help children remember more about science in museum- and homework-like activities (Crowley \& Jacobs, 2002; Palmquist \& Crowley, 2007; Valle \& Callanan, 2006). Taken together, there is good reason to believe that associative explanatory talk and Wh-questions together can support learning and subsequent remembering.

The combination of hands-on engagement with objects and elaborative talk during events may promote successful transfer for several reasons. First, conversations may provide mechanisms that make physical engagement with objects a focus of explicit learning. Second, conversations are critical to the 
process of establishing intercontextuality; parents, for example, may point out relations among objects in the first setting that can help children to see linkages between the two situations. Third, these conversations may facilitate the process of what Sigel (1993) called distancing and what Goldstone and Sakamoto (2003) called concreteness fading-learning to focus less on the specific objects and more on the abstract knowledge or concepts that can facilitate transfer. Conversations may help to make individual object-manipulation experiences part of a more integrated and cohesive cognitive representation that supports transfer. Finally, conversations may be important in helping children connect prior knowledge and new learning. When parents make associations - such as saying, "How is this different from where you sleep?" or "We get our corn at the store" - transfer becomes the subject of discussion.

\section{The Current Study}

The relations between conversational interactions and object manipulation were studied in two exhibits at The Field Museum, Chicago's natural history museum. Our research began in an exhibit designed specifically for young children: the Southwestern Pueblo and Plaza. Hands-on activities in the space depict the daily practices of the Pueblo people 800 years ago. The Field Museum exhibits depict similarities and differences in how different peoples met the challenges of daily living (e.g., shelter, food). We took advantage of this to examine transfer of knowledge between the Pueblo exhibit and a second Native American exhibit: the Pawnee Lodge.

To examine the influences of conversation, we created a set of conversation cards about objects featured prominently in the Pueblo exhibit. On one side of each card was a picture of one of the objects. On the other side were questions that invited the parents and children to label, describe, and make associations about the object pictured on the card. To investigate the influences of object manipulation, we gave some dyads physical objects to play with that were relevant to the Pueblo exhibit they would soon see. Prior to visiting the Pueblo, some dyads received both the cards and the objects, and others received only one of the two sets of materials. A control group received neither but played with objects (fossils) unrelated to the exhibits.

The two experimental manipulations allowed us to test several hypotheses regarding the contribution of parent-child conversation, object manipulation, and the combination of the two on learning and transfer. We hypothesized that the cards might lead parents to use more elaborative talk in the Pueblo. Consistent with prior work (e.g., Boland et al., 2003), our measure of elaborative talk included parents' Wh-questions about objects and prior knowledge associations that connected what the child already knew to aspects of the Pueblo exhibit. When the cards were presented in combination with the opportunity for hands-on activity with the objects from the Pueblo, we hypothesized that the children would participate more with their parents in joint talk (i.e., responding to their parents Wh-questions), and might even contribute more information spontaneously (not in response to parents' questions). We also hypothesized that the preexhibit activity with objects would result in the most joint nonverbal interaction with the objects in the Pueblo. Children's hands-on experience with the objects might prompt them to pay more attention to these same objects in the exhibit, and to participate in activities with their parents that might help them learn more about them.

In addition, we hypothesized that a combination of conversation and hands-on learning would lead children to represent the knowledge gained in the Pueblo exhibit in ways that would enhance transfer of knowledge across environments (different exhibits; museum to home). We measured transfer through the across-exhibit association parents and children made that connected information about the two exhibits. We also considered transfer from the museum to home over time. Albeit with a reduced sample size, we studied what the children were able to report in reminiscing conversations with their parents 1 day and 2 weeks after the museum visit. We hypothesized that the combination of cards and hands-on engagement with objects that had the greatest effect on learning and transfer in the museum would also lead children to be able to retrieve and report the most information across contexts over time.

\section{Method \\ Participants}

The 78 (59 female) parents and their children (41 girls; $M_{\text {child age }}=4.94$, range $=2.9-6.6$ ) who participated in this study were recruited from three sources (about one third from each): The Field Museum membership lists, three Chicago public schools, and the museum's general admission line. Parents reported (by filling out a blank on a questionnaire) that 50 children could be classified as European American, 8 Hispanic American, 7 
Asian/Asian American, and 3 African American; 10 did not provide information about race/ethnicity. All participants spoke English as their native language. The mean level of parental education was 16.76 years $(S D=3.15)$. Participants received free admission and free parking on the day of their museum visit, and a free family pass to return to the museum.

\section{Museum Setting}

The Southwestern Pueblo and Plaza includes a fire pit, clay pot, and utensils for cooking; a mano and metate for grinding corn; a storage area for drying corn; arrowheads; a straw mat for sleeping; and various children's toys and clothing. The outside of the Pueblo is a pretend cornfield with woven baskets that are used to gather the corn. Like the Pueblo, the Pawnee Earth Lodge also illustrates cooking, sleeping, and food-related cultural practices. The objects in the Lodge include a fire pit, cooking pots and utensils, a mortar and pestle for grinding meal, food storage pouches and buckets, weaponry, buffalo-robed beds, and children's toys and moccasins.

\section{Procedures}

All dyads were seen separately by the same female researcher. After they agreed to participate and provided informed consent, the procedures involved the following: the preexhibit activity, a visit to the Pueblo exhibit, a visit to the Pawnee Lodge, the family questionnaire, and the at-home memory conversations.

\section{Preexhibit Activity}

Immediately before visiting the Pueblo exhibit, all dyads participated in a 10-min session in a room located in the museum's education department. The experimental manipulation was carried out during this session. The dyads either did or did not receive several specially designed, 4 in. $\times 6$ in., laminated conversation cards, and either did or did not receive several target objects from the exhibit. In combination, these two variables yielded a 2 (cards: yes or no) $\times 2$ (objects: yes or no) experimental design; parent-child dyads were randomly assigned to one of the four cells of this $2 \times 2$ design.

As illustrated in Appendix A, one side of each conversation card featured a picture of one of six target objects. As shown in Appendix B, the other side of each card listed three to five Wh-questions about the object pictured on the card. Some of the questions were about physical and functional characteristics of the objects. Other questions invited prior knowledge associations between the object and something that families might already know. Dyads who received the cards were asked to examine the objects pictured on the cards and talk about them using the kinds of questions listed on the cards. Dyads assigned to receive objects were given all six target objects pictured in Appendix A. These dyads were asked to engage with and explore these objects in ways that might help their child understand what the objects are made of, what they are used for, and how they might be similar or different from things the dyads use in their daily lives. Dyads who received both the cards and the objects were given the cards and physical objects at the same time and heard both sets of instructions. Dyads that received neither cards nor objects served as the control participants and explored six fossils unrelated to the exhibits.

\section{Visiting the Exhibits}

The dyads did not take the preexhibit activity materials with them to the exhibits. They were escorted to the Pueblo exhibit and told they could stay as long as they liked. When they indicated they were ready to leave the Pueblo, dyads were guided to the Pawnee Lodge. We did not counterbalance the ordering of visits to the two exhibits because the Pueblo exhibit was specifically constructed for young children and was therefore likely to be more comprehensible to the children than the Pawnee Lodge, which was designed for a general audience. When they arrived at the Lodge, dyads were told to explore this home to a group of Native Americans from the Central Plains of the United States. The researcher did not mention any connections across exhibits. Dyads wore wireless microphones, and their interactions in both exhibits were audio and video recorded for coding.

\section{Family Questionnaire}

After visiting the Lodge, parents completed a brief survey about the families' prior experience(s) at The Field Museum and demographic information.

\section{Reminiscing at Home}

At the end of the exhibit visits, dyads were invited to participate in an additional (optional), 
at-home memory task. Modeled after procedures adapted from Benjamin, Haden, and Wilkerson (2010), parents were asked to reminisce with their children on two occasions, 1 day and 2 weeks following the museum visit. They were provided with instructions to ask their children to remember all that they could about their experiences in both exhibits. They were supplied with an audio recorder that was to be returned when the recordings were complete in a postage-paid mailer. Unfortunately, despite our best efforts to obtain these data (e.g., with reminder phone calls; additional incentives), only 44 families took the recorders home, and only 30 , or $68 \%$, of these families $(38 \%$ of the total sample) returned recorders with usable recordings of both memory conversations on which we could base the repeated measures analyses.

\section{Coding}

Videotaped recordings of dyads' verbal and nonverbal behaviors in the two exhibits were scored using Noldus Observer Video-Pro software (http:/ / www.Noldus.com). Independent clauses were the coding unit, with each unique or implied verb in an independent clause forming a new unit. For example: "I remember the corn stalks (one coding unit) and picking corn (second unit)." A child who said, "It's made of wood, fur, and mud" received credit for three units for each new piece of information provided (wood, fur, mud). This approach has been used in prior work (e.g., Reese, Haden, \& Fivush, 1993) to minimize the effects of language differences between older children (who may be speaking more in complete sentences) and younger children who may be providing the same amount of unique informational content, even if in different linguistic forms. Reliability estimates reflect the extent to which the coders agreed both on the number of units to be coded (that "It's made of wood, fur, and mud" is three units) and on the code type used to classify each unit (e.g., child response, child spontaneous talk). Procedures for establishing reliability were the same for all codings. Two researchers independently coded $25 \%$ of the records. Once reliability was established, no single estimate was below $80 \%$ (Cohen's kappas > .70); one coder coded the remainder of the data with checks by the second coder.

\section{Parents' Elaborative Talk in the Pueblo}

In the Pueblo, parents' elaborative talk was defined as parents' total number of Wh-questions and prior knowledge associations. Wh-questions requested new, not previously provided information (e.g., "What is this used for?"). Prior knowledge associations linked any aspect of the Pueblo to the child's prior knowledge or experience through Wh-questions ("How is this sleeping mat different from your bed at home?"), yes-no questions ("Did they have TV to watch Dora in the Pueblo, do you think?"), or statements ("We cook our dinner over a fire on our stove"). Parents' elaborative talk in the Pueblo (Wh-questions and prior knowledge associations) was subcoded as being either about the 6 target objects or about 12 other predefined nontarget objects in the Pueblo exhibit (e.g., baskets, doll, shoes, ladle, fire pit). Interrater agreement in scoring parents' elaborative talk in the Pueblo reflected substantial interrater agreement at $91.3 \%$ (kappa $=.82)$.

\section{Children's Responses to Parents' Wh-Questions in the Pueblo}

Children's responses to their parents' Wh-questions were also coded. Interrater agreement was $89.4 \%$ (kappa $=.78)$. Joint talk was then calculated by dividing the number of children's responses by the total number of their parents' Wh-questions. Computing joint talk as a proportion of total questions controlled for variation in the number of Whquestions parents asked. Children could receive credit for more than one response per parent question (e.g., the parent asks "What is this made of?" and the child says "It's made of wood, fur, and mud").

\section{Children's Spontaneous Talk in the Pueblo}

Children's correct provision of exhibit-relevant information that was not in response to a parents' question was scored as spontaneous talk. Interrater agreement was $87.6 \%(\mathrm{kappa}=.74)$.

\section{Nonverbal Behavior in the Pueblo}

Nonverbal behaviors included pointing to an object, touching an object (e.g., patting, tossing, dumping), manipulating an object (e.g., manually exploring, showing), or functionally using an object (e.g., putting the corn in the pot). Each nonverbal behavior that co-occurred with a parent's Wh-question was classified as being displayed (a) by the parent and child jointly, (b) by the parent only, or (c) by the child only. For example, if a parent picked up the corn and asked, "How should we 
cook this?" (a Wh-question) and the child took the corn and put it in the pot, this was coded as joint nonverbal behavior with a target object (corn). If the parent asked the question, but only the child touched the corn (the parent did not pick up the corn), this was coded as child-only nonverbal behavior. Interrater agreement for coding nonverbal behaviors averaged $98.1 \%(\mathrm{kappa}=.96)$. On the basis of this coding, we computed the proportion of Wh-questions asked by each parent that were accompanied by joint, parent-only, or child-only nonverbal behavior. This calculation again controlled for variation in the number of Wh-questions.

\section{Across-Exhibit Associations in the Pawnee Lodge}

To assess transfer across exhibits we coded the number of across-exhibit associations that connected information about the Pueblo peoples or the dyad's experiences in the Pueblo with aspects of the Pawnee Lodge exhibit. Parent's across-exhibit associations were subcoded as Wh-questions ("How is this house different from the one we just saw?"), yes-no questions ("This bed isn't like the one we just saw downstairs [in the Pueblo], is it?"), or statements ("They [Pawnee] slept on beds, not on the floor"). The children's across-exhibit associations were subcoded as either being responses to their parents' Wh-questions or spontaneous (not in response to a parent's question). We only coded children's responses to parents' across-exhibit association questions if the response was also an across-exhibit association (e.g., a parent asked, "How are these beds different from the beds we saw in the Pueblo?" and a child responded, "These have animal fur on them and not straw like downstairs"). Percent interrater agreement averaged 95.6\% $($ kappa $=.93)$ for parents' across-exhibit associations, $97.8 \%(\mathrm{kappa}=.95)$ for children's associative responses, and $93.2 \%$ (kappa $=.85)$ for children's spontaneous across-exhibit associations. Joint acrossexhibit associations were computed as the number of across-exhibit association responses children made divided by the total number of their parents' across-exhibit Wh-question associations.

\section{At-Home Reminiscing Conversations}

To assess transfer from museum to home, we examined coded transcripts of the memory conversations dyads recorded 1 day and 2 weeks after the museum visit. The coding of parents' talk focused on the frequency of elaborative Wh-questions. The children's reports during reminiscing were scored as either responses to parents' Wh-questions or spontaneous. Interrater agreement for parents' Wh-questions was 92\% (kappa $=.88)$, for children's responses was 95.7\% (kappa $=.92)$, and for children's spontaneous talk was $89.1 \%$ (kappa $=.85$ ). Again, joint talk was computed by dividing the number of child responses by the total number of parents' Wh-questions.

\section{Results Preliminary Analyses}

Preliminary analyses were aimed at identifying if any background characteristics, gender, or age were correlated with the dependent measures. First, a series of 2 (cards) $\times 2$ (objects) $\times 2$ (child gender) analyses of variance (ANOVAs) conducted for each dependent measure revealed no main or interactive effects of gender; therefore, child gender is not considered further. There were also no main effects or interactions of recruitment strategy for any of the dependent measures. Additional 2 (cards) $\times 2$ (objects) ANOVAs confirmed that random assignment resulted in groups that were approximately equal on child age and the other background characteristics. As shown in the bottom of Table 1, there were also no differences in the amount of time dyads spent in the Pueblo or Pawnee Lodge, $F_{\mathrm{s}}<.28, p \mathrm{~s}>.60$. Furthermore, correlational analyses tested the association between each variable listed in Table 1 and each dependent measure. The only significant correlations were between total time spent in the Pueblo exhibit and the following dependent measures (all $p s<.01$ ): parents' elaborative talk about target objects and nontarget objects in the Pueblo ( $r \mathrm{~s}=.48$ and .46 , respectively), joint nonverbal engagement with target and nontarget objects in the Pueblo ( $r \mathrm{~s}=.42$ and .41 , respectively), child-only engagement with nontarget objects in the Pueblo $(r=.30)$, and parents' association statements in the Pawnee Lodge $(r=.41)$. Time in the Pueblo was used as a covariate in the main analyses of these six dependent variables to which it was significantly correlated. Neither age nor any other background variable significantly correlated with the dependent measures.

\section{Main Analyses}

To test our hypotheses, we first examined how parents' and children's verbal and nonverbal behaviors in the Pueblo may have been affected by the preexhibit activities. Then, we addressed whether 
Table 1

Demographic and Background Variables and Total Time Spent in the Pueblo Exhibit

\begin{tabular}{|c|c|c|c|c|}
\hline \multirow[b]{2}{*}{ Variable } & \multicolumn{4}{|c|}{ Experimental group } \\
\hline & Cards only & Objects only & Cards + objects & Control \\
\hline \multicolumn{5}{|l|}{ Child gender } \\
\hline Female & 10 & 10 & 10 & 11 \\
\hline Male & 9 & 11 & 10 & 7 \\
\hline Age (years) & $4.80 \quad(1.14)$ & $4.82(1.14)$ & $5.31(0.95)$ & $4.78(0.68)$ \\
\hline Paternal education & $17.55 \quad(3.03)$ & $16.66(3.36)$ & $16.37(2.75)$ & $16.37(5.37)$ \\
\hline Maternal education $^{a}$ & $17.33 \quad(1.68)$ & $16.11(3.02)$ & $15.88(2.94)$ & $17.76(2.33)$ \\
\hline $\begin{array}{l}\text { Parents' knowledge } \\
\text { before visit }^{\mathrm{b}}\end{array}$ & 3.16 (1.46) & $2.90(1.30)$ & $3.30(1.49)$ & $3.00(1.49)$ \\
\hline $\begin{array}{l}\text { Children's knowledge } \\
\text { before visit }^{\mathrm{b}}\end{array}$ & 1.84 (1.06) & $1.42(0.67)$ & $1.55(0.88)$ & $1.33(0.84)$ \\
\hline $\begin{array}{l}\text { Parent rating of learning } \\
\text { after visit }^{\mathrm{a}}\end{array}$ & $5.42(0.90)$ & $4.80(1.16)$ & $5.05(0.94)$ & $4.77(0.94)$ \\
\hline $\begin{array}{l}\text { Parent rating of child learning } \\
\text { after visit }^{\mathrm{a}}\end{array}$ & 4.68 (1.15) & $4.23(1.51)$ & $4.95(1.27)$ & $4.44(0.98)$ \\
\hline $\begin{array}{l}\text { Average number of parent and } \\
\text { child visits to the Field Museum }\end{array}$ & $7.84(11.39)$ & $5.50(6.95)$ & $5.27(9.35)$ & $5.02(5.79)$ \\
\hline Total time in Pueblo (min) & $11.74 \quad(5.21)$ & $11.54(4.99)$ & $11.82(6.49)$ & $10.70(5.02)$ \\
\hline $\begin{array}{l}\text { Total time in Pawnee Earth } \\
\text { Lodge (min) }\end{array}$ & $11.16 \quad(4.10)$ & $9.56(3.09)$ & $11.25(3.33)$ & $10.86(5.01)$ \\
\hline
\end{tabular}

Note. Standard deviations are in parentheses.

${ }^{a} \mathrm{~A}$ main effect of objects was obtained, $F(1,67)=6.50, p<.01$, such that despite random assignment, maternal education was lower for families who received objects in the preexhibit activity. ${ }^{b}$ Parent ratings of prior knowledge on a 1-7 scale, with the rating of 1 being knew very little and 7 being knew a lot.

the preexhibit activities, and the interactions in the Pueblo they engendered, might have supported transfer of learning across environments (different exhibits; museum to home) and time. All hypotheses were tested using 2 (cards: yes, no) $\times 2$ (objects: yes, no) ANOVAs. A main effect of cards indicates that parent-child dyads that received conversation cards during the preexhibit activity differed on the dependent measures from the other dyads who did not receive the cards. A main effect of objects indicates that dyads that received the objects in the preexhibit activity differed on measured variables from dyads who did not receive the objects. An interaction points to differences on dependent measures among dyads who participated in the four preexhibit activities: cards only, objects only, cards + objects, and Control (fossils).

\section{Parent-Child Interactions in the Pueblo}

Our first hypothesis was that the conversation cards would lead parents to engage in the most elaborative talk in the Pueblo. The top portion of Table 2 displays the mean frequency of parents' elaborative talk in the Pueblo. As hypothesized, there was a significant main effect of cards, $F(1,73)=4.62$, $p<.05, \eta^{2}=.06$; parents who received the cards engaged in more elaborative talk about target objects in the Pueblo $(M=7.38, S D=6.70)$ than parents who did not receive cards $(M=4.76, S D=4.07)$. There was no significant main effect of objects or an Objects $\times$ Cards interaction for elaborative talk about target objects in the Pueblo, Fs $<1.87$, ps $>.18$. We also examined elaborative talk about nontarget objects; there were no significant effects, $F \mathrm{~s}<0.67$, ps $>.41$ (see Table 2). In sum, the conversation cards supported parents' elaborative talk about the six target objects in the Pueblo.

The second hypothesis tested was that the combination of the conversation cards and objects in the preexhibit activities would result in the most joint talk between parents and children in the Pueblo. Children gave very few incorrect responses $(M=$ $0.07, S D=0.16)$. Therefore, the analyses of joint talk focused on the number of children's correct responses to their parents' Wh-questions divided by the total number of parents' Wh-questions. Also, due to low frequencies of joint talk among some dyads, we combined across target and nontarget objects for these analyses. The means for joint talk in the Pueblo are presented in the top portion of Table 3 . The main effect of objects was significant, $F(1,74)=6.01$, 
Table 2

Mean Frequencies of Talk in the Museum

\begin{tabular}{|c|c|c|c|c|}
\hline \multirow[b]{2}{*}{ Conversation variable } & \multicolumn{4}{|c|}{ Experimental group } \\
\hline & Cards only & Objects only & Cards + objects & Control \\
\hline \multicolumn{5}{|c|}{ Elaborative and spontaneous talk in Pueblo exhibit } \\
\hline \multicolumn{5}{|c|}{ Parent elaborative talk } \\
\hline About target objects & $7.37(6.46)$ & $5.95(4.39)$ & $7.40 \quad(7.08)$ & $3.38(3.25)$ \\
\hline About nontarget objects & $5.68(5.20)$ & $7.28(5.90)$ & $6.40(8.06)$ & $6.05(4.26)$ \\
\hline Child spontaneous talk & $11.05(6.38)$ & $8.57(4.33)$ & $11.75(10.38)$ & $7.56(3.13)$ \\
\hline \multicolumn{5}{|c|}{ Across-exhibit associations in Pawnee exhibit } \\
\hline \multicolumn{5}{|l|}{ Parent } \\
\hline Wh-questions & $3.83(4.94)$ & $0.95(1.40)$ & $1.75(1.88)$ & $1.11(1.49)$ \\
\hline Yes-No questions & $5.56(4.65)$ & $3.04(2.75)$ & $5.00 \quad(5.05)$ & $1.61(1.24)$ \\
\hline Statements & $3.94(3.96)$ & $3.10(2.33)$ & 5.80 & 1.38 (1.09) \\
\hline Child spontaneous & $1.39(1.85)$ & $0.50(1.05)$ & $1.20 \quad(2.44)$ & $0.33(0.48)$ \\
\hline
\end{tabular}

Note. Standard deviations are in parentheses.

Table 3

Mean Proportions of Verbal and Nonverbal Behaviors in the Exhibits and at Home

\begin{tabular}{|c|c|c|c|c|}
\hline \multirow[b]{2}{*}{ Behaviors } & \multicolumn{4}{|c|}{ Experimental group } \\
\hline & Cards only & Objects only & Cards + objects & Control \\
\hline \multirow{2}{*}{\multicolumn{5}{|c|}{$\begin{array}{l}\text { Joint verbal behaviors in the exhibits } \\
\text { Joint talk }\end{array}$}} \\
\hline & & & & \\
\hline Joint talk in Pueblo & $0.56(0.33)$ & $0.80(0.53)$ & $0.67(0.67)$ & $0.38(0.30)$ \\
\hline Across-exhibit associations & $2.11(2.96)$ & $0.70(1.41)$ & $0.65(1.03)$ & $0.27(0.46)$ \\
\hline \multicolumn{5}{|c|}{ Nonverbal behaviors in the Pueblo } \\
\hline \multicolumn{5}{|c|}{ Target objects } \\
\hline Joint nonverbal & $0.19(0.25)$ & $0.13(0.22)$ & $0.29(0.29)$ & $0.09(0.15)$ \\
\hline Child-only nonverbal & $0.12(0.21)$ & $0.15(0.30)$ & $0.06(0.23)$ & $0.15(0.28)$ \\
\hline \multicolumn{5}{|l|}{ Nontarget objects } \\
\hline Joint nonverbal & $0.26(0.26)$ & $0.28(0.25)$ & $0.26(0.31)$ & $0.21(0.26)$ \\
\hline Child-only nonverbal & $0.14(0.25)$ & $0.07(0.10)$ & $0.08(0.16)$ & $0.09(0.12)$ \\
\hline \multicolumn{5}{|l|}{ Memory conversations } \\
\hline \multicolumn{5}{|l|}{ Joint talk during reminiscing } \\
\hline 1 day & $1.75(0.65)$ & $2.46(0.47)$ & $2.06(0.96)$ & $1.77(0.81)$ \\
\hline 2 weeks & $1.82(1.11)$ & $1.37(0.43)$ & $1.83(0.80)$ & $0.73(0.39)$ \\
\hline
\end{tabular}

Note. Standard deviations are in parentheses.

$p<.05, \eta^{2}=.08$; dyads who received the objects engaged in more joint talk $(M=0.74, S D=0.60)$ than those who did not receive the objects $(M=0.47$, $S D=0.31$ ). There was no significant main effect of cards or an Objects $\times$ Cards interaction for joint talk in the Pueblo, Fs $<1.93, p s>.17$ (see Table 3). Thus, presenting the objects, alone or in combination with the cards, led to the most parent-child joint talk in the Pueblo.

Our third hypothesis was that receiving both the cards and objects would lead children to talk the most, not only in response to their parents' questions (as indexed by joint talk, above), but also spontaneously. We focused these analyses on children's spontaneous talk that was not elicited by their parents' questions, and again combined across talk about target and nontarget objects due to low frequencies of spontaneous talk for some children. The means are listed in Table 2. There was a significant main effect of cards, $F(1,73)=4.67, p<.05$, $\eta^{2}=.06$; children who were involved in the cards preexhibit activity made more spontaneous comments $(M=11.42, S D=8.56)$ than those who did not receive the cards $(M=8.10, S D=3.80)$. There 
was no significant main effect of objects or an interaction for children's spontaneous comments in the Pueblo, Fs $<.19, p s>.65$ (see Table 2). Therefore, children's spontaneous talk in the Pueblo exhibit was helped by the cards either if they had been presented alone or with the objects.

Finally, in the Pueblo, we considered the parents' and children's hands-on engagement with objects. We hypothesized that the dyads who received objects would engage in the most joint nonverbal interactions with objects in the Pueblo. Table 3 reports the proportion of the time one of the following three nonverbal behaviors co-occurred with parents' Wh-questions: joint, parent only, or child only. Parent-only nonverbal engagement was low $(M=0.05)$ and thus is not considered further. There was a significant main effect of cards, $F(1,71)=4.97, p<.05, \eta^{2}=.07$; more joint hands-on engagement with target objects was observed among dyads who received cards $(M=0.24, S D=0.27)$ than among those who did not receive the cards $(M=0.11, S D=0.18)$. For joint hands-on engagement with target objects, neither the main effect of objects nor the interaction were significant, $F_{\mathrm{S}}<2.23, \mathrm{ps}>.14$. The preexhibit activities also did not affect child-only nonverbal engagement with target objects, Fs $<.83$, ps $>$.37. Moreover, for the nontarget objects, there were neither main effects nor interactions for joint nonverbal engagement, $F \mathrm{~s}<.33, p \mathrm{~s}>.56$, or childonly nonverbal engagement, $F_{\mathrm{S}}<1.12, p_{\mathrm{S}}>.29$ (see Table 3). In sum, the most joint engagement with target objects in the Pueblo was observed among parents and children who received the cards, regardless of whether they also received the objects.

\section{Linkages and Transfer Across Exhibits}

Transfer of learning across environments was first assessed by looking at the extent of across-exhibit associations made by parents and children within the museum. The initial hypothesis was that the combination of the cards and objects in the preexhibit activity would be most helpful in fostering knowledge about the Pueblo peoples that could be used, in turn, to make sense of the Pawnee exhibit. However, as reported above, parents who received the cards in the preexhibit activity engaged in the most elaborative and joint talk with their children in the Pueblo. Therefore, it seemed possible that the cards, whether presented with or without the objects, would lead to the most across-exhibit associations.
The bottom portion of Table 2 reports the number of parents' across-exhibit associations for the three forms: (a) Wh-questions, (b) yes-no questions, and (c) statements. Parents who received the cards made more of all three forms of across-exhibit associations compared with those who did not receive the cards: Wh-questions (with cards: $M=2.76$, $S D=3.79$; without: $M=1.02, S D=1.43$ ); yes-no questions (with cards: $M=5.27, S D=4.75$; without: $M=2.38, S D=2.27$ ); and statements (with cards: $M=4.90, S D=4.40$; without: $M=2.31, S D=2.00$ ). The significant main effects of cards for across-exhibit associations were as follows: Wh-questions, $F(1$, $74)=7.65, \quad p<.01, \eta^{2}=.09 ;$ yes-no questions, $F(1,74)=12.12, p<.001, \eta^{2}=.14$; and statements, $F(1,74)=12.01, p<.001, \eta^{2}=.14$. Only in the analysis of statement associations was there also a significant main effect of objects, $F(1,74)=5.54$, $p<.02, \eta^{2}=.07 ;$ more across-exhibit statement associations were made by parents who received objects $(M=4.41, S D=3.91)$ than parents who did not $(M=2.70, S D=3.10)$. All other main effects of objects and interactions were not significant, $F_{\mathrm{s}}<2.27, p \mathrm{~s}>$.13. In sum, the results demonstrate that not only did the cards engender more elaborative talk in the Pueblo, but without specifically prompting them to do so, the cards also led parents to ask more questions and make more statements that linked information across the Pueblo and Pawnee Lodge exhibits. The objects also facilitated parents' across-exhibit statement associations.

We next examined if transfer across exhibits would be evident in dyad's joint across-exhibit associative talk. As shown in Table 3, dyads who received both the objects and the cards engaged in the most joint associative talk connecting the exhibits. The main effect of cards, $F(1,72)=5.11, p<.05$, $\eta^{2}=.07$, was qualified by a Cards $\times$ Objects interaction, $F(1,72)=5.70, p<.05, \eta^{2}=.07$; the main effect of objects was not significant, $F(1,72)=1.73$, $p=.21$. Thus, it was the combination of cards and objects that led to joint discussions connecting the exhibits.

As reported in the bottom of Table 2, children provided some spontaneous across-exhibit associations. There was a significant main effect cards, $F(1,74)=5.35, p<.05, \eta^{2}=.07$; children who were in the cards preexhibit activity made more spontaneous associations $(M=1.29, S D=2.15)$ compared to children who had not received cards $(M=0.42$, $S D=0.82)$. There was no significant main effect of objects or an interaction, $F \mathrm{~s}<.22$, $p \mathrm{~s}>.64$. Therefore, the children who were in the cards preexhibit activity encoded information about the Pueblo in a 
manner that they could then transfer and use to understand aspects of the Pawnee exhibit. For example, the conversations may have helped to embed the individual elements into a more coherent narrative that facilitated linking across contexts (Engle, 2006).

\section{Transfer from the Museum to Home}

The reminiscing conversations dyads recorded at home provide additional information about transfer. Essentially, they offer data concerning the amount of information children can retain and use to report about their learning experiences days and weeks later. As mentioned above, only a subset of the sample (30 families) recorded both of the memory conversations at home at the 1-day and 2-week delays and could thus be included in the repeated measures analyses reported here. Although the families who completed both memory conversations may have been different from those who did not, we did not detect any such differences on the demographic or dependent measures in this study, $F \mathrm{~s}<2.05, p \mathrm{~s}>.16$. Nevertheless, it is appropriate to view these analyses as exploratory based on the small number of participants per group (see top of Table 4).

We hypothesized that the combination of preexhibit activities with cards and objects that had the greatest effect on learning and transfer in the museum would also lead to the highest levels of subsequent reporting over time. Given the results presented thus far, we could also expect parents who received the cards in the museum might demonstrate the most elaborative talk during reminiscing at home. In keeping with prior work on reminiscing, we focused on a key measure of an elaborative parental reminiscing style: parents' Whquestions. The top half of Table 4 illustrates the mean number of parents' Wh-questions during reminiscing at the 1-day and 2-week delays. As shown, there was a significant main effect of delay ( 1 day, 2 weeks), $F(1,26)=9.38, p<.01, \eta^{2}=.36$, indicating a decrease in questions over time, but there were no interactions with delay, $\operatorname{Fs}(1,26)<1.41$, $p s>.25$. Also, parents who received cards and/or objects in the preexhibit activities asked more Whquestions over time than those who did not (fossil/ control group), as was indicated by the significant main effects of cards and objects, $F s(1,26)<7.08$, $p \mathrm{~s}<.01, \eta^{2} \mathrm{~s}=.17$ to .22 , but no Cards $\times$ Object interaction, $F(1,26)=1.87, p=.18$. Thus, there was evidence, in the form of parents' Wh-questions, that the effects of the preexhibit activities extended beyond the museum walls to affect the at-home conversations.

Next, we examined the extent to which joint talk during reminiscing differed as a function of preexhibit activity. We anticipated that receiving the cards, which led to the most joint talk in the museum (see above), would also result in the most joint talk during reminiscing. As shown in Table 3, there was a significant main effect of time, $F(1$, 26) $=18.06, p<.001, \eta^{2}=.41$; the amount of joint talk during reminiscing declined over 2 weeks. The effect of time was qualified by a Cards $\times$ Time interaction, $F(1,26)=13.32, p<.001, \eta^{2}=.34$; all other main and interactive effects were not significant, $F \mathrm{~s}(1,26)<.46, p s>.50$. During reminiscing, dyads who received the cards in the preexhibit activities engaged in significantly more joint talk overall across the delay interval in comparison to dyads who did not receive the cards.

Finally, if the preexhibit activities had facilitated children's abilities to transfer what they had learned in the museum across environments and time, we expected this to be evident in their spontaneous productions during reminiscing. As shown in

Table 4

Mean Frequencies of Parents' and Children's Talk Reminiscing Talk at Home

\begin{tabular}{|c|c|c|c|c|}
\hline \multirow[b]{2}{*}{ Memory conversations } & \multicolumn{4}{|c|}{ Experimental group } \\
\hline & Cards only $(n=6)$ & Objects only $(n=6)$ & Cards + objects $(n=9)$ & Control $(n=9)$ \\
\hline \multicolumn{5}{|l|}{ Parents' Wh-questions } \\
\hline 1 day & $11.63(5.90)$ & $11.33(6.30)$ & $18.27(10.40)$ & $8.00(3.51)$ \\
\hline 2 weeks & $7.33(5.68)$ & $6.50(3.08)$ & $13.00 \quad(7.05)$ & $8.11(3.88)$ \\
\hline \multicolumn{5}{|c|}{ Children's spontaneous reporting } \\
\hline 1 day & $7.87(6.17)$ & $18.11(8.44)$ & $10.27(10.39)$ & $12.10(7.85)$ \\
\hline 2 weeks & $7.33(9.60)$ & $10.33(5.85)$ & $14.10(11.59)$ & $8.11(4.88)$ \\
\hline
\end{tabular}

Note. Standard deviations are in parentheses. 
Table 4, children spontaneously reported less information about their museum experiences over time, with a significant main effect of time, $F(1$, $26)=8.92, p<.01, \eta^{2}=.59$. However, the children who received the cards actually reported more information 2 weeks after the museum visit than at the 1-day delay, with the effects of time for children's spontaneous contributions being qualified by a Cards $\times$ Time interaction, $F(1,26)=6.87, p<.01$, $\eta^{2}=.14$. Over the delay, children who received the cards preexhibit activities were able to access and report more about their museum experiences, even without their parents' questions to elicit the information. Taken together, the reminiscing results provide further support for the notion that the cards preexhibit activities promoted both learning and transfer.

\section{Discussion}

\section{Summary of Findings}

The results of this study may contribute in several ways to research on the effects of conversation on children's learning and retention of information, and the relation between hands-on learning and learning from others. In addition, the results offer information about mechanisms of learning and transfer in informal contexts. Finally, the work makes an important contribution to discussions regarding methods for studies of informal learning in naturalistic contexts. We begin with a summary of the key findings and then discuss each of the contributions.

Our experimental manipulations consisted of giving brief instructions and the conversation cards, the target objects, both, or neither to parents and children before entering the exhibits. All dyads then explored the two museum exhibits freely. Our observations of how the preexhibit activities affected behavior and conversation in both exhibits, as well as during reminiscing conversations later at home, led to several important findings. First, the conversation cards did influence parents' conversations and actions in the Pueblo. As predicted, the cards appeared to cue parents to talk in more elaborative ways and enable more spontaneous talk by children in the Pueblo. Dyads that received the cards also engaged in more joint nonverbal activities with objects in the Pueblo than dyads who did not receive cards. Second, families transferred more information between the first exhibit, the Pueblo, and the second, the Pawnee Lodge, if they received the cards. This occurred even though the cards did not specifically prompt families to make such con- nections across exhibits. Third, for the sample of participants who completed the memory conversations at home, those who had received the cards demonstrated transfer from museum to home, even up to 2 weeks later. Fourth, there were effects of the objects preexhibit activity, although they were somewhat more subtle: Dyads who interacted with exhibit objects before entering the exhibits showed the most joint talk in the Pueblo.

\section{Conversations and Object Manipulation}

Overall, we found that learning from direct experiences with objects and learning through conversations with others are intertwined. What children take away from their experiences is determined by a combination of what they do and what they talk about. Although children can learn a great deal on their own, conversations with parents (or other adults, siblings, or peers) also greatly influence the content, retention, recall, and transfer of what they learn. This conceptualization is linked to a large literature concerning children's hands-on learning with objects (e.g., Leinhardt et al., 2002; Paris \& Hapgood, 2002; Ramey-Gassert \& Walberg, 2006), as well as an extensive set of studies on the influences of conversations on children's understanding and remembering of events (e.g., Fivush, Haden, \& Reese, 2006; Haden, 2010).

The example questions on our conversation cards were sufficient to promote elaborative conversation, although they provided less explicit instruction than in prior studies (e.g., Benjamin et al., 2010; Boland et al., 2003). The effects of the cards on conversations and actions in the Pueblo were consistent, regardless of whether the cards accompanied the physical objects in the preexhibit activity. Parents who received the cards before visiting the exhibit readily incorporated Wh-questions and associations into their conversational style with their children. Wh-questions focus a child's attention on aspects of an event and help the parent determine what the child does and does not know. Requests for names, descriptions, actions, explanations, and so forth, can help a child construct a coherent representation of an experience in memory. Parents' associations that link an unfolding experience to what the child already knows can help the child make sense of that which is novel or unfamiliar by guiding the child to attach his or her prior knowledge to an experience in a way that facilitates comprehension (Boland et al., 2003; Crowley et al., 2001; Tessler \& Nelson, 1994). Together, asking Wh-questions and making associations 
can increase what is learned and how accessible that information is in the future.

The effects of the cards preexhibit activity also extended to the children's spontaneous talk in the Pueblo about objects that drew their attention and/ or what they wanted to learn more about. Moreover, the cards preexhibit activity resulted in the most parent-child joint engagement with objects in the exhibit. Fostering children's talk, particularly in the context of joint parent-child engagement with objects, is important. Research on event memory (e.g., Haden et al., 2001; Tessler \& Nelson, 1994) recommends that talk in the context of joint handson engagement with objects can be expected to be strongly linked to successful learning. Clearly, children can learn through their direct actions on objects. However, especially when the objects are novel, and are themselves representations of a larger body of knowledge, parents' talk and actions may play a central role in children reaching a greater understanding and in helping them to distance themselves from the specific aspects of the experience. For example, as children manipulated objects in the Pueblo, their parents talked about and demonstrated the role these objects played in daily life. Some objects in the exhibit were artifacts and replicas of pieces discovered by archeologists. Joint activity with such objects in combination with conversation might affect children's understanding the process of scientific discovery, such as what leads us to know how these different objects fit into the lives of the Pueblo peoples.

Interestingly, the conversation cards resulted in the most joint nonverbal behaviors, and the presentation of objects prior to exhibit entry led to the most parent-child joint talk. Why was this the case? We suggest that receiving the objects before visiting the exhibit may have altered what children found to be new in the exhibit. Having already explored the objects during the preexhibit activity, these children were now better prepared to discuss them with their parent. Importantly, joint discussions, particularly ones in which the parents' Wh-questions are followed by the children's verbal provision of the requested information, may be a critical mechanism for learning and memory development (e.g., Haden et al., 2001; Hedrick et al., 2009; Tessler \& Nelson, 1994). Taken together, these findings suggest that both preexhibit activities were instrumental in beginning a chain of talk and actions that may be critical for substantial learning and transfer. Joint talk in the exhibit served as a chance to augment understanding gained from manipulating objects in the preexhibit activity, just as joint non- verbal behaviors offered new possibilities for learning after the cards activity.

In addition to the effects on talk and actions related to the target objects, we tested if the preexhibit activities led to more talk and action with other, nontarget objects in the Pueblo but did not find this to be the case. In retrospect, however, not finding such generalization is not surprising. We chose target objects that were highly salient and central to the depiction of life in the Pueblo. The objects we selected could be compared with functionally similar objects used by the Pawnee that were on exhibit in the Lodge; this helped to facilitate the study of transfer.

\section{Transfer}

The preexhibit activities, and the interactions in the Pueblo that resulted from them, contributed to transfer of learning to a new exhibit, the Pawnee Earth Lodge. To analyze transfer across the two exhibits, we asked if dyads who participated in the preexhibit activities gained knowledge that was portable that they could connect to new opportunities for learning. We looked at talk that made explicit connections between the dyads' experiences in the Pueblo to the Pawnee Earth Lodge. As evidence of transfer, we found that parents and children who received the cards in the preexhibit activity made the most associations that linked the two exhibits. These dyads also engaged in the most joint parent-child talk comparing and contrasting the Pueblo and Pawnee Lodge. Importantly, dyads were not asked or prompted to make these connections. Thus, we think about these results in terms of a chaining of experiences. The cards activity led to both elaborative talk and joint activity among dyads in the Pueblo, which in turn may have driven understanding and the representation of experiences in ways that made them especially accessible and transferrable to another context.

A critical factor in successful learning and transfer is whether knowledge that is gained in one context is presented or represented in a manner in which it can be accessed in another context (Bransford \& Schwartz, 1999; Gentner, Loewenstein, \& Thompson, 2003; Gick \& Holyoak, 1983). For example, explanations and activities that help to link items in one context into a coherent, meaningful narrative are substantially more likely to promote transfer than activities focused on individual elements (Engle, 2006). In this regard, conversations may be particularly important to the process of establishing intercontextuality, helping children link 
relevant prior knowledge, expectations, and experiences to the present learning context. Conversations affect how children think about both past and future experiences. For instance, conversations make direct experience a topic of explicit learning. They provide the opportunity for knowledge to be explicated, that is, to become a topic of conscious reflections, and ultimately, abstraction (Karmiloff-Smith, 1991). Associations that relate current experiences to existing knowledge or previous experiences make transfer the subject of the discussion. Our results indicate that the elaborative talk prompted in the Pueblo led dyads to extend what they learned in the first exhibit to better understand the second.

A portion of the sample also recorded memory conversations about their museum experiences 1 day and 2 weeks following the visit. What is reported in these conversations is an amalgam of semantic memory (exhibit-related information) and episodic memory (what parents and children experienced together in the exhibits). In fact, these memory conversations provide a way of looking at the process of integration across individual learning episodes and the conditions that may promote it (see Bauer, King, Larkina, Varga, \& White, 2012, for discussion). Likewise, we and others argue that memory conversations can be a robust and meaningful measure of transfer of knowledge (e.g., Benjamin et al., 2010; Callanan \& Jipson, 2001; Leinhardt et al., 2002), in this case from museum to home over time. Yet little developmental work has considered such contextual and temporal dimensions that can characterize the distance of transfer of knowledge (Barnett \& Ceci, 2002; Klahr \& Chen, 2011). Parents who received the cards continued to ask more Wh-questions about the museum experiences weeks later in the context of reminiscing in comparison to their counterparts. Moreover, children who received the cards preexhibit activity remembered their museum visit the best, and even showed evidence of hypermnesia, reporting more information spontaneously 2 weeks after the museum visit than they had after a 1-day delay. Of course, these findings must be interpreted with caution, because only a subset of the families returned the recordings of the memory conversations. Also, subsequent experiences and conversations at home might have indeed helped to increase children's reporting. A limitation of our work is that it cannot specifically address questions about how different activities and interaction patterns at home extend learning beyond the museum walls-outside of the memory conversations themselves. Future work could assess how museum visits might serve as a catalyst that ultimately leads to further knowledge and understanding, particularly in STEM, across learning experiences and contexts.

\section{Research on and Methods for Studying Informal Learning}

Our work illustrates advantages of combining experimental and observational research in informal, naturalistic settings. Many studies of learning and parent-child interaction have stressed the need to observe informal learning in unaltered, natural contexts (see, e.g., Falk \& Dierking, 2000; HirschPasek, Golinkoff, Berk, \& Singer, 2003). The richness of the interactions between parents and children, and of the concomitant conversations, requires detailed observations that are not easily captured in simpler laboratory studies. However, in such unconstrained situations, it can be difficult to ascertain causal relations and hence to provide information that might generalize to other contexts (Allen et al., 2007). Our methods illustrate a way to combine the strengths of both approaches. The experimental manipulations occurred in a brief intervention before parents and children explored the exhibits. We were then able to follow the sequelae of these manipulations to learn how talking about and interacting with objects influenced behavior and promoted learning and transfer. Importantly, the control group provided a naturalistic yet rigorous measure of dyads' interactions and learning without any intervention.

Finally, the results may also contribute to museum design. The amount and type of information to provide about exhibits is a subject of substantial discussion (e.g., Falk \& Dierking, 2000). For example, some museums provide detailed information about the relevant history or science that has motivated the exhibit, allowing the visitor to learn more or pursue additional interests beyond the exhibit. However, particularly in museums and exhibits for children, visitors may rarely have time to read or look at lengthy explanations. Our results suggest that when parent-child interactions in exhibits may be limited to the attention span of a young child, providing short, specific information about key objects or features in the exhibit may be especially useful. Although scientific or historical detail is certainly important, it may be even more important to provide actionable information that helps parents to support their children's learning and explanation. In this regard, we note that The Field Museum replaced the more detailed 
informational sheets in the Pueblo exhibit with displays that resembled the cards that we used in this study. Of course, visitors can still choose to seek out additional information.

Moreover, there are considerable cultural variations in parent-child conversations (e.g., Bell et al., 2009; Fivush \& Haden, 2003; Gaskins, 2008; Miller, Fung, Lin, Chen, \& Boldt, 2012), and this may be especially true in exhibits that focus on culture and cultural comparison. But such differences could not be addressed in the context of this study and our homogenous sample. In fact, the relatively high educational level of the parents in this study sets limits on the generalizability of our findings. Parents with different levels of schooling talk with their children differently in museum settings (e.g., Siegel, Esterly, Callanan, Wright, \& Navarro, 2007; Tenenbaum \& Callanan, 2008). Moreover, some of the kinds of questions coded here as elaborative (e.g., when a parent asks a questions he or she knows the answer to) might be used infrequently by some cultural groups (Rogoff, 1990). Given the perspective that conversational interactions are important for learning in informal settings, it would make sense that children's learning may vary depending on the different experiences they have talking and interacting with their parents around STEM-related activities. Addressing the need to expand research and understanding of cultural and individual variations in informal learning approaches and outcomes (Bell et al., 2009; Tenenbaum \& Callanan, 2008) could also have implications for broadening future participation in STEM and increasing the diversity of the pipeline of individuals entering science fields.

In conclusion, we think our project is a good example of use-inspired research (Newcombe et al., 2009). We asked questions relevant to basic science, but part of the initial motivation for asking those questions was a desire to understand and to work with a museum to enhance their exhibits and visitors' experiences. Both parties gained from taking this perspective on the research (cf. Callanan, 2012; Diamond, Luke, \& Uttal, 2009); the museum constructed alternate displays that directed parents to think about what they could discuss with their children, and we welcomed the opportunity to study the influences of these changes on children's and parents' conversations, actions, and learning. The present research could provide information for researchers, parents, and other educators alike about how to enhance interactions in rich, naturalistic environments in ways that can promote learning and transfer of knowledge.

\section{References}

Allen, S., Gutwill, J., Perry, D. L., Garibay, C., Ellenbogen, K. M., Heimlich, J. E., . . . Klein, C. (2007). Research in museums: Coping with complexity. In J. H. Falk, L. D. Dierking, \& S. Foutz (Eds.), In principle, in practice: Museums as learning institutions (pp. 229-248). Lanham, MD: AltaMira Press.

Auslander, J. (2001). Embodied mathematics. American Scientist Online, 89. Retrieved from http://www.ameri canscientist.org/template/BookshelfReviews/issue/396

Barnett, S. M., \& Ceci, S. J. (2002). When and where do we apply what we learn? A taxonomy for far transfer. Psychological Bulletin, 128, 612-637. doi:10.1037/0033-2909. 128.4.612

Bauer, P. J., King, J. E., Larkina, M., Varga, N. L., \& White, E. A. (2012). Characters and clues: Factors affecting children's extension of knowledge through integration of separate episodes. Journal of Experimental Child Psychology, 111, 681-694. doi:10.1016/j.jecp.2011.10.005

Bell, P., Lewnstein, B., Shouse, A. W., \& Feder, M. A. (Eds.). (2009). Learning science in informal environments: People, places, and pursuits. Washington, DC: The National Academies Press.

Benjamin, N., Haden, C. A., \& Wilkerson, E. (2010). Enhancing building, conversation and learning through parent-child interactions in a children's museum. Developmental Psychology, 46, 502-515. doi:10.1037/a0017822

Boland, A. M., Haden, C. A., \& Ornstein, P. A. (2003). Boosting children's memory by training mothers in the use of an elaborative conversational style as event unfolds. Journal of Cognition and Development, 4, 39-65. doi:10.1080/15248372.2003.9669682

Bransford, J. D., \& Schwartz, D. L. (1999). Rethinking transfer: A simple proposal with multiple implications. In A. Iran-Nejad \& P. D. Pearson (Eds.), Review of research in education (Vol. 24, pp. 61-101). Washington, DC: American Educational Research Association.

Callanan, M. A. (2012). Conducting cognitive developmental research in museums: Theoretical issues and practical considerations. Journal of Cognition and Development, 13, 137-151. doi:10.1080/15248372.2012.666730

Callanan, M. A., \& Jipson, J. L. (2001). Explanatory conversations and young children's developing scientific literacy. In K. Crowley, C. D. Schunn, \& T. Okada (Eds.), Designing for science: Implications from professional, instructional, and everyday science (pp. 21-49). Mahwah, NJ: Erlbaum.

Crowley, K., Callanan, M., Jipson, J., Galco, J., Topping, K., \& Shrager, J. (2001). Shared scientific thinking in everyday parent-child activity. Science Education, 85, 712-732. doi:10.1002/sce.1035

Crowley, K., \& Jacobs, M. (2002). Islands of expertise and the development of family scientific literacy. In G. Leinhardt, K. Crowley, \& K. Knutson (Eds.), Learning conversations in museums (pp. 333-356). Mahwah, NJ: Erlbaum.

Diamond, J., Luke, J. J., \& Uttal, D. H. (2009). Practical evaluation guide: Tools for museums and other informal educational settings. Lanham, MD: AltaMira Press. 
Eberbach, C., \& Crowley, K. (2009). From everyday to scientific observation: How children learn to observe the biologist's world. Review of Educational Research, 79, 3968. doi:10.3102/0034654308325899

Ellenbogen, K. M. (2002). Museums in family life: An ethnographic case study. In G. Leinhardt, K. Crowley, \& K. Knutson (Eds.), Learning conversations in museums (pp. 81-101). Mahwah, NJ: Erlbaum.

Engle, R. (2006). Framing interactions to foster generative learning: A situative account of transfer in a community of learners classroom. Journal of the Learning Sciences, 15, 451-498. doi:10.1207/s15327809jls1504_2

Falk, J., \& Dierking, L. (2000). Learning from museums. Visitor experiences and the making of meaning. Walnut Creek, CA: AltaMira Press.

Fivush, R., \& Haden, C. A. (Eds.). (2003). Autobiographical memory and the construction of a narrative self: Developmental and cultural perspectives. Mahwah, NJ: Erlbaum.

Fivush, R., Haden, C. A., \& Reese, E. (2006). Elaborating on elaboration: The role of maternal reminiscing style in cognitive and socioemotional development. Child Development, 77, 1568-1588. doi:10.1111/j.1467-8624. 2006.00960.x

Gaskins, S. (2008). Designing exhibitions to support families' cultural understandings. Exhibitionist, 27, 11-19.

Gentner, D., Loewenstein, J., \& Thompson, L. (2003). Learning and transfer: A general role for analogical encoding. Journal of Educational Psychology, 95, 393-408. doi:10.1037/0022-0663.95.2.393

Gick, M. L., \& Holyoak, K. J. (1983). Schema induction and analogical transfer. Cognitive Psychology, 15, 1-38. doi:10.1016/0010-0285(83)90002-6

Glenberg, A. M., Brown, M., \& Levin, J. R. (2007). Enhancing comprehension in small reading groups using a manipulation strategy. Contemporary Educational Psychology, 32, 389-399. doi:10.1016/j.cedpsych.2006.03. 001

Goldstone, R. L., \& Sakamoto, Y. (2003). The transfer of abstract principles governing complex adaptive systems. Cognitive Psychology, 46, 414-466. doi:10.1016/ S0010-0285(02)00519-4

Haden, C. A. (2010). Talking about science in museums. Child Development Perspectives, 4, 62-67. doi:10.1111/j. 1750-8606.2009.00119.x

Haden, C. A., Ornstein, P. A., Eckerman, C. O., \& Didow, S. M. (2001). Mother-child conversational interactions as events unfold: Linkages to subsequent remembering. Child Development, 72, 1016-1031. doi:10.1111/14678624.00332

Hedrick, A. M., San Souci, P., Haden, C. A., \& Ornstein, P. A. (2009). Mother-child joint conversational exchanges during events: Linkages to children's memory reports over time. Journal of Cognition and Development, 10, 143-161. doi:10.1080/15248370903155791

Hirsch-Pasek, K., Golinkoff, R. M., Berk, L. E., \& Singer, D. (2003). A mandate for playful learning in preschool: Presenting the evidence. New York, NY: Oxford University Press.
Karmiloff-Smith, A. (1991). Beyond modularity. Cambridge, MA: MIT Press.

Klahr, D., \& Chen, Z. (2011). Finding one's place in transfer space. Child Development Perspectives, 5, 196-204. doi:10.1111/j.1750-8606.2011.00171.x

Leinhardt, G., Crowley, K., \& Knutson, K. (Eds.). (2002). Learning conversations in museums. Mahwah, NJ: Erlbaum.

McGuigan, F., \& Salmon, K. (2006). The influence of talking on showing and telling: Adult-child discussion and children's verbal and nonverbal recall. Applied Cognitive Psychology, 20, 365-381. doi:10.1002/acp.1183

McNeil, N. M., \& Uttal, D. H. (2009). Rethinking the use of concrete materials in learning: Perspective from development and education. Child Development Perspectives, 3, 137-139. doi:10.1111/j.1750-8606.2009.00093.x

Miller, P. J., Fung, H., Lin, S., Chen, E. C. H., \& Boldt, B. R. (2012). How socialization happens on the ground: Narrative practices as alternate socializing pathways in Taiwanese and European-American families. Monographs of the Society for Research in Child Development, 77(1).

Narayanan, N. H., \& Hegarty, M. (2000). Communicating dynamic behaviors: Are interactive multimedia presentations better than static mixed-mode presentations? In M. Anderson, P. Cheng, \& V. Harslev (Eds.), Theory and application of diagrams. Lecture Notes in Artificial Intelligence 1889 (pp. 178-194). Berlin, Germany: Springer.

National Science Board. (2010). NSB report: Preparing the next generation of STEM innovators. Retrieved from http:/ / tinyurl.com/263elpn

Newcombe, N. S., Ambady, N., Eccles, J., Gomez, L., Klahr, D., Linn, M., . . Mix, K. (2009). Psychology's role in mathematics and science education. American Psychologist, 64, 538-550. doi:10.1037/a0014813

Núñez, R. E. (2000, July). Mathematical idea analysis: What embodied cognitive science can say about the human nature of mathematics. Proceedings at the conference of the International Group for the Psychology of Mathematics Education, Hiroshima, Japan.

Palmquist, S., \& Crowley, K. (2007). From teachers to testers: How parents talk to novice and expert children in a natural history museum. Science Education, 91, 783804. doi:10.1002/sce.20215

Paris, S. G., \& Hapgood, S. E. (2002). Children learning with objects in informal learning environments. In S. G. Paris (Ed.), Perspectives on object-centered learning in museums (pp. 37-54). Mahwah, NJ: Erlbaum.

Piaget, J. (1970). Science of education and the psychology of the child (D. Coltman, Trans.). London, England: Longman.

Ramey-Gassert, L., \& Walberg, H. J. (2006). Reexamining connections: Museums as science learning environments. Science Education, 78, 345-363. doi:10.1002/sce.373078 0403

Reese, E., Haden, C. A., \& Fivush, R. (1993). Mother-child conversations about the past: Relationships of style and memory over time. Cognitive Development, 8, 403-430. doi:10.1016/S0885-2014(05)80002-4 
Rigney, J. C., \& Callanan, M. A. (2011). Patterns in parent-child conversations about animals at a marine science center. Cognitive Development, 26, 155-171. doi:10. 1016/j.cogdev.2010.12.002

Rogoff, B. (1990). Apprenticeship in thinking: Cognitive development in social context. New York, NY: Oxford University Press.

Ross, B. H. (1989). Distinguishing types of superficial similarities: Different effects on the access and use of earlier problems. Journal of Experimental Psychology: Learning, Memory Cognition, 15, 456-468. doi:10.1037/ 0278-7393.15.3.456

Siegel, D., Esterly, J., Callanan, M., Wright, R., \& Navarro, P. (2007). Conversations about science across activities in Mexican-decent families. International Journal of Science Education, 29, 1447-1466.

Sigel, I. E. (1993). The centrality of a distancing model for the development of representational competence. In R. Cocking \& A. Renninger (Eds.), The development and meaning of psychological distance (pp. 141-158). Hillsdale, NJ: Erlbaum.

Tenenbaum, H. R., \& Callanan, M. A. (2008). Parents' science talk to their children in Mexican-descent families residing in the USA. International Journal of Behavioral Development, 32, 1-12. doi:10.1177/0165025407084046

Tessler, M., \& Nelson, K. (1994). Making memories: The influence of joint encoding on later recall by young children. Consciousness and Cognition, 3, 307-326. doi:10. 1006/ccog.1994.1018

Uttal, D. H., Amaya, M., Maita, M. R., Hand, L. L., O'Doherty, K., \& DeLoache, J. S. (2013). It works both ways: Transfer difficulties between manipulatives and written subtraction solutions. Child Development Research, 2013, 13. doi:10.1155/2013/216367

Uttal, D. H., Liu, L. L., \& DeLoache, J. S. (2006). Concreteness and symbolic development. In L. Balter \& C. Tamis-LeMonda (Eds.), Child psychology: A handbook of contemporary issues (2nd ed., pp. 167-184). Philadelphia, PA: Psychology Press.

Uttal, D. H., O’Doherty, K., Newland, R., Hand, L. L., \& DeLoache, J. S. (2009). Dual representation and the linking of concrete and symbolic representations. Child Development Perspectives, 3, 156-159. doi:10.1111/j. 1750-8606.2009.00097.x

Valle, A., \& Callanan, M. A. (2006). Similarity comparisons and relational analogies in parent-child conversations about science topics. Merrill-Palmer Quarterly, 52, 96-124. doi:10.1353/mpq.2006.0009

Vygotsky, L. S. (1978). Mind in society: The development of higher psychological processes. Cambridge, MA: Harvard University Press.

Zimmerman, H. T., Reeve, S., \& Bell, P. (2009). Family sense-making practices in science center conversations. Science Education, 94, 478-505. doi:10.1002/sce.20374

\section{Appendix A}

Target Objects as Pictured on the Conversation Cards

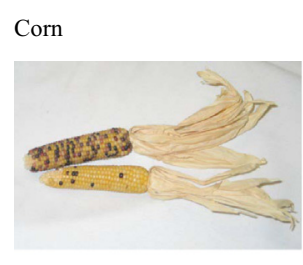

Sleeping Mat

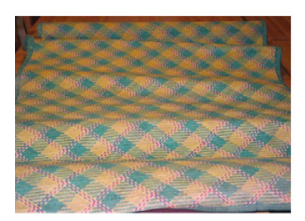

Coil Pot

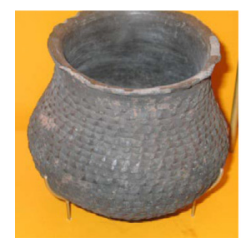

Mano and Metate

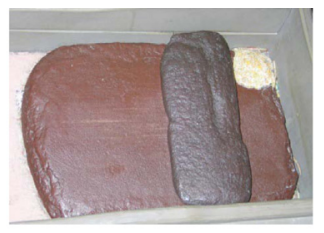

Pueblo

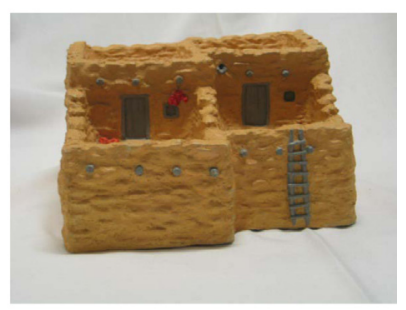

Arrowhead

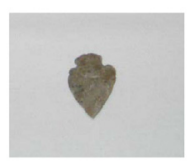




\section{Appendix B}

\section{Text on Conversation Cards}

Ear of Corn

Where does corn grow?

What do you think corn needs to grow?

How does corn get harvested?

What do you do with corn once you pick it?

How is this corn different from the corn we eat today?

Sleeping Mat

How do you think it would feel to sleep on this mat?

What is it made of?

How is it different from where you sleep?

\section{Cooking Pot}

What could this pot be used for?

How is this pot different from the pots we cook with?

Why do you think they made the inside of the pot smooth and kept the outside of the pot rough?

Mano (Hand-Stone) and Metate (Trough)

What do you think this is used for?

What is the mano and metate made of?

Why do you think the mano and metate are made in this shape?

Once you grind up corn, what do you do with it?

What do we eat that is made of corn?

\section{Pueblo}

What is the Pueblo made of?

What did they do in the different rooms in the Pueblo?

How is the Pueblo different from where we live?

Arrowhead

What do you think this is made of?

What do you think this would be attached to?

What was this tool used for?

Why would people hunt?

What kind of animal would have been hunted with this arrowhead? 